\title{
Los servicios turísticos y el imaginario del turista, caso de estudio Ambato
}

The tourist services and tourist imaginary, Ambato 'study case

1 Johanna Micaela Ortiz Martínez

iD https://orcid.org/0000-0002-2691-2214

Universidad Técnica de Ambato, Facultad de Ciencias de la Educación, Carrera de Turismo. Ambato, Ecuador

jortiz4316@uta.edu.ec

2 María Fernanda Viteri Toro

https://orcid.org/0000-0003-2600-7115

Universidad Técnica de Ambato, Facultad de Ciencias de la Educación, Carrera de

Turismo. Ambato, Ecuador

mf.viteri@uta.edu.ec

3 Camilo Francisco Torres Oñate (iD) https://orcid.org/0000-0002-9411-5401

Universidad Técnica de Ambato, Facultad de Ciencias de la Educación, Carrera de

Turismo. Ambato, Ecuador

cf.torres@uta.edu.ec

4 Yadira Alexandra Proaño Gómez $\quad$ (iD) https://orcid.org/0000-0003-1189-5316

Universidad Regional Autónoma de Los Andes, Facultad de Dirección de Empresas,

Carrera de Turismo. Ambato, Ecuador

ya.proano@uta.edu.ec

Artículo de Investigación Científica y Tecnológica

Enviado: 24/12/2021

Revisado: $29 / 12 / 2021$

Aceptado: $12 / 01 / 2022$

Publicado:08/03/2023

DOI: https://doi.org/10.33262/concienciadigital.v6i1.4.1999

Cítese:

Ortiz Martínez, J. M., Viteri Toro, M. F., Torres Oñate, C. F., \& Proaño Gómez, Y. A. (2023). Los servicios turísticos y el imaginario del turista, caso de estudio Ambato. ConcienciaDigital, $6(1.4)$ https://doi.org/10.33262/concienciadigital.v6i1.4.1999

298-315.

CONCIENCIA DIGITAL, es una Revista Multidisciplinar, Trimestral, que se publicará en soporte electrónico tiene como misión contribuir a la formación de profesionales competentes con visión humanística y crítica que sean capaces de exponer sus resultados investigativos y científicos en la misma medida que se promueva mediante su intervención cambios positivos en la sociedad. https://concienciadigital.org

La revista es editada por la Editorial Ciencia Digital (Editorial de prestigio registrada en la Cámara Ecuatoriana de Libro con No de Afiliación 663) www.celibro.org.ec 
Palabras claves:

imaginario turístico, oferta turística, servicios turísticos, destino, perspectiva

\section{Keywords:}

tourist imaginary, tourist offer, tourist services, destination, outlook

\section{Resumen}

Introducción. El presente artículo se centra en el estudio del imaginario que poseen los turistas respecto a un destino, tomando como referencia Ambato. El imaginario, es un proceso que busca interpretar de forma subjetiva las perspectivas que el turista tiene solo con el hecho de referirse con mención a algún destino. Es decir que se busca analizar lo que se proyecta en la mente del viajero previo a visitar un destino, considerando que, para cada turista, existirá un destino idóneo. Objetivo. Caracterizar el imaginario del turista proyectado en los destinos y su oferta turística. Metodología. La investigación posee un enfoque mixto; Es cuantitativa en el sentido de que se recopilo datos estadísticos y desde la perspectiva cualitativa se discute los resultados desde la hermenéutica del turismo. Su alcance es descriptivo fenomenológico correlacional. Con un dice no experimental de corte transversal. Resultados. El destino con mayor acogida posicionado en el imaginario del turista por sus atractivos turísticos es Estados Unidos y México en Latinoamérica, y Turquía con el estudio del turista respecto al continente europeo. Conclusión. Para tomar la decisión de viaje tiene como referencia la proyección del destino en ámbitos como política, social, ambiental, económicos, cultural y seguridad, mismos que son los elementos que conforman el imaginario del turista e inciden directamente en la oferta de un espacio geográfico determinado.

\section{Abstract}

Introduction. This article focuses on the study of the imaginary that tourists have regarding a destination, taking Ambato as a reference. The imaginary is a process that seeks to subjectively interpret the perspectives that the tourist has only with the fact of referring to a destination. In other words, it seeks to analyze what is projected in the mind of the traveler prior to visiting a destination, considering that, for each tourist, there will be an ideal destination. Objective. Characterize the imaginary of the tourist projected in the destinations and their tourist offer. Methodology. The research has a mixed approach; It is quantitative in the sense that statistical data was collected and from a qualitative perspective the results are discussed from the hermeneutics of tourism. Its scope is descriptive phenomenological correlational. With a non-experimental crosssectional design. Results. The most popular destination in the 
tourist imagination due to its tourist attractions is the United States and Mexico in Latin America, and Turkey with the study of tourists in relation to the European continent. Conclusion. To make the travel decision, it is based on the projection of the destination in areas such as political, social, environmental, economic, cultural and security, which are the elements that make up the tourist's imagination and directly affect the offer of a given geographical space.

\section{Introducción}

El Turismo es una actividad de ocio que es desarrollada por el turista, por ende, la elección para visitar un destino depende mucho de la oferta que el mismo tenga. Dicha oferta se considera en el imaginario del turista, para una elección de viaje final.

El termino imaginario, proviene del latín imaginarius, y se entiende como algo que no existe o que es representado por la mente. El imaginario es un conjunto de imágenes mentales que surgen como un fenómeno individual pero compartido por una sociedad.

Esta representación, cuando es percibida a través de los sentidos y causan una impresión de la realidad de forma consciente o inconsciente se conoce como percepción. Sin embargo, cuando existe una percepción del entorno, esta se implanta en la imaginación del turista con el fin de que esta se convierta en una realidad (Decasper \& Servalli, 2016).

Cuando esta percepción crea algo significativo en más de un turista, se considera como imaginario social, donde este conjunto de emociones, sensaciones, símbolos, y más crean una tendencia, posicionándose así en la mente de las personas que buscan viajar (Pons, 2017)

Además, para establecer un imaginario, estos se han sido modificados y perfeccionados por dos corrientes, que se detallan a continuación.

\section{Corriente Francesa}

Esta perspectiva, establecida por Durckheim busca posicionar a la imaginación como el eje principal para comprender a la sociedad. Aquí, se establece una correlación fundamental entre religión y el conjunto social. Se busca que el imaginario tenga un sentido simbólico y mítico influenciado por un factor arquetípico. Además de revalorizar la imaginación en el trascurso de los cambios modernos donde la sociedad ha tenido un cambio de visión racional y objetiva. 


\section{Corriente Iberoamericana}

Esta perspectiva desarrollada en España busca comprender la realidad y el orden social a través de procesos sistémicos enfocados en la conducta empírica.

Además, el imaginario se compone de elementos, que se detallan a continuación:

\section{Expresión visual}

Hace referencia a las imágenes de todo tipo reales o imaginarias

\section{Dimensión lingüística}

Consideradas todas las trasmisiones orales.

\section{Ideario}

Entendiéndose al proceso del pensamiento que genera fantasías, deseos, aspiraciones.

Es decir, que, dentro del imaginario social, existen manifestaciones, deseos y tendencias vinculadas netamente con la interacción del ser humano y el viaje, considerándose a la misma como Imaginario turístico. En otros términos, se puede definir al imaginario turístico como la visión del viajero respecto a las actividades de ocio en un destino (Goycoolea, 2016).

Sin embargo, otra definición que se acuña al término mencionado una representación de un deseo respecto a un lugar turístico que determina la visita de un destino de forma favorable o negativa, se considera como una relación entre el entorno físico, los elementos y el turista (Zamudio, 2019).

De ahí que, surge el termino Imagen turística, la misma que se entiende como una construcción mental donde predomina las creencias del turista respecto al destino de visita, donde a más de una representación visual, el turista genera un sentimiento y conocimiento respecto a los elementos de destino (Millet, 2016).

En Turismo, existe la prestación de un servicio, y producto, entendiéndose que servicio es una actividad que busca satisfacer una necesidad, y por lo general es intangible. A su vez producto se considera a un bien material que puede ser percibido por el cliente (Castellucci, 2016). Dicho consumidor, busca que tanto Producto como Servicio sean de calidad para considerar la visita a un lugar turístico.

La calidad es un factor determinante para que el consumidor genere en su imaginario y posicione un servicio, considerando que si la esta cubre una necesidad o deseo que el cliente posee, y esta logra satisfacerle, el mismo cliente difundirá la marca de nuestro servicio o producto, dicha publicidad se posicionara en el imaginario de los potenciales 
turistas, y aunque no será la principal motivación, influenciará en la misma para tomar una decisión de visita a un destino turístico (Antonietti, 2017).

La motivación se puede definir como un estado personal, que activa una conducta y anima a una persona a portarse o realizar algo que este desea (Araujo \& Sevilla,2017). En el ámbito turístico, se define a la motivación como una conducta que influye al turista para la realización de un viaje.

La Organización Mundial del Turismo (OMT), considera que para desplazarse de un lugar a otro fuera del entorno habitual, existen tres tipos de motivaciones:

\section{Motivaciones personales}

Es el entusiasmo que el ser humano posee para realizar una actividad sin ser influenciado por su entorno. En este grupo existe la necesidad de generar conocimientos a través de la experiencia turística o tener contacto con el medio natural, con el fin de generar un equilibro físico-mental para con el mismo (Sancho, 1994).

\section{Motivaciones familiares}

Considerado como un anhelo que se busca cumplir junto con el núcleo familiar. La necesidad de establecer convivir con los miembros de la familia se hace presente para crear lazos de unión entre los mismos y compartir tiempo de calidad.

\section{Motivaciones sociales}

Es un factor que regula la conducta del ser humano bajo la influencia de la sociedad y determinan el comportamiento dentro de la misma. Dentro de estas se encuentran las necesidades de imitación, donde el consumidor de forma consciente o inconsciente seguir el actuar de la sociedad con el objetivo de encajar en el círculo social al que se pertenece (Valdez, 2002). Por el contrario, la necesidad de singularidad crea en el consumidor el menester de distinguirse de los otros. Estas necesidades van ligadas puesto que una vez que se cumpla la singularidad, la sociedad va a buscar imitar al turista, creando así una motivación social.

De igual forma se puede decir que dentro de estas proyecciones, el turista proyecta un destino considerando los aspectos de un país. Estos son:

\section{Aspecto Político}

Entendido como un conglomerado de procesos gubernativos que ejercen en un contexto histórico y cultural que tratan de establecer una reciprocidad entre las prácticas y reglas con competencia política entre el gobierno y los ciudadanos. En la relación con el turismo, influyen en las normativas y restricciones de entradas a un país, además de la relación 
entre sus gobiernos y convenios para la factibilidad de la actividad turística (Casanova, 2016).

\section{Aspecto Religioso}

Este ámbito hace referencia a las prácticas religiosas que predominan en una zona geográfica determinada. En varias situaciones este aspecto es un motivador para la realización de las practicas turísticas, aunque de igual forma, este puede ser un limitante para lo mismo (Mantecón y Álvarez, 2019).

\section{Aspecto Económico}

Considerado como la producción y consumo de productos y servicios que se desarrollan en un país, por lo que este tiene una dotación monetaria y por ende expansión industrial y comercial, es decir, es el poder monetario de un país. Cuando este es considerado una potencia, mueve mayor flujo de turistas por la seguridad del valor de su moneda (Magadán, 2016).

\section{Aspecto Ambiental}

El ámbito ambiental es entendido como un elemento que surge como producto, servicio o actividad que se relaciona con el medio ambiente. En la actualidad, la demanda turística busca tener acercamientos con destinos que tengan un desarrollo sostenible y sustentable que no afecte al medio natural, preocupándose por su preservación.

\section{Aspecto Cultural}

Dentro del ámbito cultural, mismo que es definido como aquellos elementos que sirven como expresiones o modelos en las que una sociedad de conceptualiza debido a sus costumbres, tradiciones y creencias, además de otros elementos que conforman la cultura de un grupo social determinad, comprendiendo así su forma de vestir, su alimentación, sus creencias y rituales (Echeverría, 2019).

\section{Servicios turísticos}

En el aspecto turístico, Sancho (1994) comenta que se considera a los servicios turísticos como un conjunto de bienes materiales o inmateriales en un espacio geográfico determino, para facilitar la estancia del visitante en dicho lugar y permitir que el mismo disfrute de un atractivo dentro de un área determinada.

Los elementos que conforman la oferta turística son: 


\section{Planta turística}

Son los establecimientos que prestan servicios turísticos (Ministerio de Turismo [MINTUR], 2018b). Dentro de se encuentra:

\section{Alojamiento}

Es una entidad que brinda el servicio de hospedaje, es decir, $\mathrm{n}$ servicio dedicado a permitir la pernoctación del turista. Esta actividad turista brinda una prestación de una habitación a cambio de una remuneración económica (MINTUR, 2021).

\section{Restauración}

También denominado alimentación y bebidas. Este establecimiento expende o suministra al turista con condumios. Dentro de esta planta turística, se encuentra en su clasificación las cafeterías, bares, discotecas, restaurantes, plazas de comida, foodtruck o establecimientos móviles y servicio de catering (MINTUR, 2021.).

\section{Transporte}

Consideradas compañías que permiten la movilidad del turista, donde existe un conductor que cuenta con permisos legales para realizar esta actividad en vehículos legalmente habilitados por la autoridad competente. La movilidad puede ser marítima, aérea o terrestre.

\section{Intermediarios}

Consideradas todas las empresas, entidades o personas que sirven como mediador entre el destino y el turista. Dentro de este, se encuentran las agencias de viajes.

\section{Servicios complementarios}

Todo tipo de servicio que facilite la actividad turística en la zona, sin ser netamente relacionados con este ámbito. Consideradas como tal, las entidades de seguridad, bancarios, de salud, etc.

\section{Infraestructura}

Considerado al conjunto restante de establecimientos y elementos que facilitan la estancia del turista en el destino. Además de la planta turística, comprende la viabilidad, comunicación y servicios básicos que son indispensables en el desarrollo de la vida (González, 2016).

Así, la planta turística forma parte de la oferta turística, la cual además se define como un contiguo de elementos que componen un producto turístico. Este último, se entiende 
como un recurso o atractivo turístico que, al contar con bienes y servicios, en conjunto motivan el desplazamiento o visita del turista (Carvajal \& Lemoine, 2018). El producto turístico, se compone de los elementos de la oferta turística ya mencionados, y adicionalmente de Recursos y Atractivos Turísticos.

\section{Recurso Turístico}

Se define como un elemento natural o cultural que no ha tenido intervención humana, por lo que no cuenta con infraestructura ni planta turística (Sancho, 1994). Aunque este elemento tiene potencial, por sí solo no logra crear una motivación de visita en el turista.

Los recursos turísticos según Navarro (2015) se clasifican en:

\section{Sitios Naturales}

Considerados los sitios geográficos con características naturales, paisajísticas, y de carácter ambiental que no han tenido modificaciones o intervención humana.

\section{Manifestaciones}

Consideradas las expresiones y manifestaciones culturales de una zona determinada que cuentan con historia y pasado ancestral. Dentro de esta categoría se destacan las expresiones manifestadas a través del folclor. Entendiéndose que el folclor abarca toda expresión oral como leyendas, mitos, relatos y expresiones gastronómicas (Camara \& Morcate, 2015).

\section{Atractivo Turístico}

Por el contrario, el atractivo se define como un recurso turístico que cuenta con planta turística e infraestructura modificada por el ser humana por lo que motiva el desplazamiento del visitante. Los atractivos se clasifican por jerarquías, la categoría más básica es el recurso, pues este como ya se mencionó, es un elemento sin apoyo de una estructura turística.

Los atractivos de Jerarquía I, son aquellos elementos que, aunque ya constan en el inventario de atractivos, aun no tienen el potencial suficiente para motivar una visita turística por sí solos, estos sirven como un complemento a otros atractivos turísticos (MINTUR, 2017).

Los atractivos de Jerarquía II, son aquellos atractivos que tienen alguna singularidad, y en caso de existir un desplazamiento por parte del turista, aunque este no sea su atractivo de interés principal puede estar considerado para una posible visita. 
Los atractivos de Jerarquía III, son aquellos atractivos que tiene una característica excepcional por lo que por sí solos o junto otros atractivos, es capaz de motivar al turista para ser visitado, por lo general atraen a turistas nacionales e internacionales.

Los atractivos de Jerarquía IV, son aquellos atractivos que son excepcionales, por lo que dicha característica motiva a la visita de turistas principalmente internacionales, por lo que este atractivo es de reconocimiento mundial (MINTUR, 2018a).

De esta forma, la influencia en la decisión para visitar un destino turístico depende mayormente de los atractivos que existan en el sitio, acompañados de una infraestructura con planta turística que permita una estancia agradable en el visitante. Ecuador, por su posición geográfica privilegiada, cuenta con un atractivo de categoría de jerarquización VI (Ricaurte, 2019). Como ejemplo de esto, las Islas Galápagos son un destino que motiva el desplazamiento turístico en los visitantes, sin embargo, pese a que este atractivo está en territorio nacional, el mayor interés de visita surge por parte de los turistas internacionales (MINTUR, 2017).

Por el contrario, en el imaginario del turista que radica en un país tercermundista la motivación de viaje se da a destinos ubicados en países del primer mundo, siendo el destino predilecto Estados Unidos. Este país al reflejar una oferta turística completa, con mayor calidad y sobre todo de mayor categoría, es un destino que se vende solo por lo que atrae a los turistas ecuatorianos, prefiriendo este destino que, además, es internacional (González, 2016).

Como ya se mencionó antes, la motivación social, donde el turista busca una aceptación por parte de un grupo social y encajar en este, posicionan en su imaginario la visita al mencionado destino americano. Adicionalmente, este posicionamiento, ha conseguido que, sin necesidad de una publicidad a gran escala, los destinos principales dentro de Estados Unidos de América se lleguen a ofertar a nivel global (García, 2021).

En este contexto es importante resalta que las decisiones de viaje como se expone en el modelo planteado por Crompton (1992), donde el autor plantea que el turista es quien elegí un destino, tras tomar una decisión racional. En esta decisión como menciona Valdez (2002), quien sustenta este modelo, considera que además influyen factores externos como el marketing y la información que otros turistas comparten con sus colegas; así mismo influyen las experiencias en el destino, y lo que el visitante investigue sobre el destino previo a visitarlo, lo que pertenece a los factores internos.

Además, este modelo parte de un destino posible hasta llegar a una decisión final para visitar un lugar. 


\section{Figura 1}

Modelo de Crompton

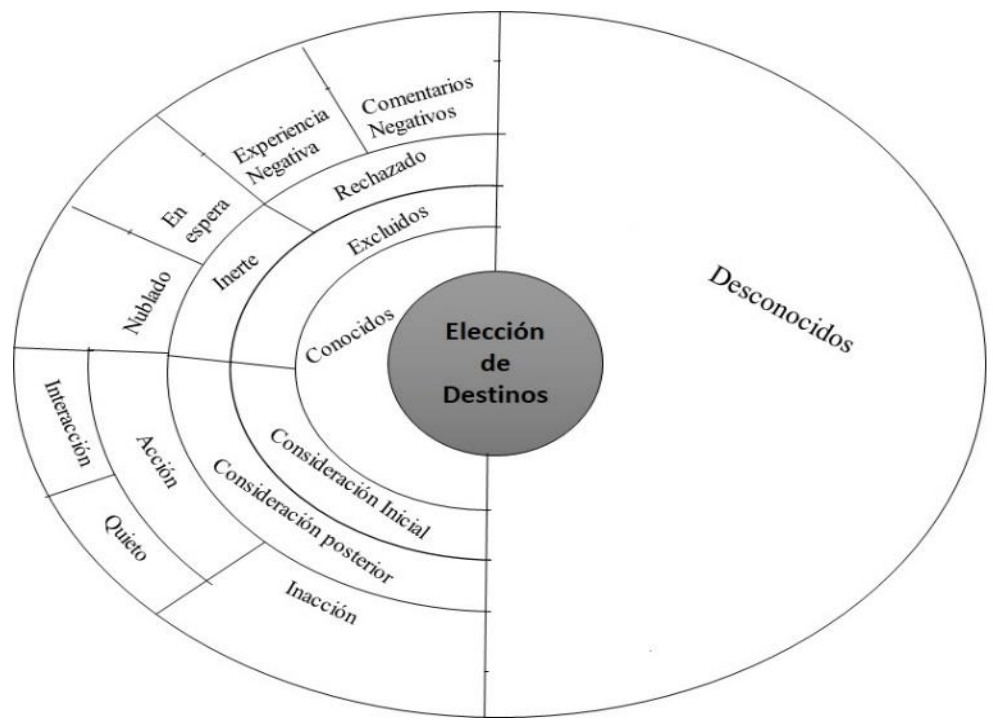

Fuente: Ortiz (2021)

Los destinos se clasifican en conocidos y desconocidos. El ultimo mencionado, queda descartar por el turista al no tener información de este por ser ignoto. Dentro de los destinos conocidos, se subdividen en excluidos, son sitios donde no existe suficiente publicidad para motivar al turista a visitarlos (Valdez, 2002). Esta categoría engloba los destinos rechazados debido a que el turista ha tenido una experiencia negativa o este ha escuchado comentarios desfavorables.

En este sentido, según datos del GEOVIT en el año 2018, el flujo de salida en este caso, del turista ambateño, indica mayor movimiento hacia la capital del territorio ecuatoriano, esto puede ser debido a la facilidad y cercanía, por lo que la movilización es accesible permitiendo un mayor desplazamiento para el desarrollo de la actividad turística, pese a que el turista ambateño aspira realizar turismo en el Ecuador insular.

Respecto al flujo de salida de los turistas respecto a un destino internacional, datos del INEC del año 2020, indican que en el último año ha existido 508.095 salidas, siendo estos ecuatorianos que visitan los Estados Unidos de América, y España principalmente.

\section{Metodología}

El presente estudio se llevó a cabo aplicado un diseño mixto. Es decir, su aspecto cuantitativo se ve reflejado en la recopilación datos estadísticos y desde la perspectiva cualitativa se discute los resultados desde la hermenéutica del turismo. Su alcance es 
descriptivo fenomenológico correlacional. Con un dice no experimental de corte transversal.

Para su desarrollo, se estableció 4 etapas, mismas que comprenden la realización de entrevistas para proceder con el desarrollo de las encuestas y su respectiva validación e interpretarlas desde la hermenéutica del turismo para caracterizar el imaginario del turista en una zona geográfica determinada.

\section{Etapa 1.- Entrevista a las agencias de viajes}

En esta etapa, se realizó un primer acercamiento entre el investigador y los gerentes/propietarios de las agencias de viajes, donde se obtuvo información sobre los datos más ofertados y vendidos por las mismas.

La información que se pretendía conocer era acerca de los destinos turísticos más comercializados a nivel mundial, así como aquellos destinos nacionales que se mercantilizan con mayor frecuencia.

Además, la realización de la entrevista permitió tomar como referente aquellos destinos que se podrían considerar como posible mercado potencial, y posteriormente desarrollar una encuesta para obtener los datos necesarios para el desarrollo del presente trabajo.

\section{Etapa 2.- Encuesta}

La encuesta desarrollada tras haber realizado una entrevista previa, parte con 5 ítems de ámbito demográfico; posteriormente se desarrolló el ámbito mercado emisor, que comprenden 7 ítems con preguntas cerradas; y el ámbito turístico conformado con 15 ítems con opciones de respuestas basadas en la escala de Likert para determinar la importancia de varios aspectos en la proyección de la imagen turista de un destino turístico. Conformando así un instrumento de 27 ítems, con opciones de respuesta variadas.

\section{Etapa 3.- Validación de instrumentos}

Tras haber estructurado la encuesta, se procedió a realizar una validación cualitativa por parte de docentes investigadores y profesionales del área turística, puesto que al ser este un proyecto investigativo y al haber planteado la encuesta bajo criterios académicos, se requería la validación de estos.

Tras receptar la respuesta por parte de los expertos, se continuó con una corrección y modificación de los instrumentos, considerando las sugerencias por parte de estos, y manteniendo los criterios, objetivos y esencia de las variables que formaron parte de las encuestas. 
Adicionalmente estadísticamente se obtuvo la fiabilidad del instrumento tras la aplicación del Alfa de Cronbach, mismo que determina el resultado del coeficiente de una totalidad de las aplicaciones para definir la ausencia de errores en la prueba. Su interpretación corresponde los siguientes datos:

Tabla 1

Interpretación de Cronbach

\begin{tabular}{ll}
\hline \multicolumn{1}{c}{ Variación numérica } & \multicolumn{1}{c}{ Interpretación } \\
\hline Entre $1,0-0,9$ & Instrumento de medición excelente \\
Entre $0,9-0,8$ & Instrumento bueno \\
Entre $0,8-0,7$ & Instrumento aceptable \\
Entre $0,7-0,6$ & Instrumento débil \\
Entre $0,6-0,5$ & Instrumento pobre \\
$<0,5$ & Instrumento no aceptable \\
\hline
\end{tabular}

Nota: Interpretación del Coeficiente de Cronbach

Para fiabilidad del instrumento aplicado en base a la estadística de Alfa De Cronbach se lo determino con preguntas directas a las variables de estudio, obteniendo un análisis de 0,8 lo que se interpreta como un instrumento bueno.

Tabla 2

Análisis de fiabilidad

\begin{tabular}{r|r|r}
\hline $\begin{array}{c}\text { Alfa de } \\
\text { Cronbach }\end{array}$ & $\begin{array}{c}\text { Alfa de Cronbach basada en } \\
\text { elementos estandarizados }\end{array}$ & $\begin{array}{c}\text { N de } \\
\text { elementos }\end{array}$ \\
\hline .824 & .842 & 9 \\
\hline
\end{tabular}

Nota: Datos obtenidos del Programa estadístico SPSS

\section{Etapa 4}

\section{Caracterización del imaginario}

De esta forma se caracteriza el imaginario del turista proyectado en los destinos y su oferta turísticos aplicando la hermenéutica del turismo, con una descripción fenomenológica, permitiendo se describa que elementos, decisiones, motivos llevan al turista a visitar un destino en particular desde una correlación entre el ámbito demográfico y el resto de los ámbitos relacionados con las variables directas de estudio. 


\section{Resultado}

\section{Etapa 1.- Entrevista a las agencias de viajes}

Tras el levantamiento de información para determinar los destinos ofertados y con mayor comercialización, se obtuvo que en el contexto internacional se mercantiliza Miami Orlando, seguido por México - Cancún respecto a América, y España y Turquía en lo que se refiere al continente europeo.

Dentro del contexto nacional, las agencias de viajes venden con mayor fuerza tours por Galápagos, y estadías en hoteles all inclusive como Decamerón y Hillary Resort.

\section{Etapa 2.- Correlación y análisis de variables}

\section{Tabla 3}

\section{Análisis de Resultados}

\begin{tabular}{|c|c|c|}
\hline Variables correlacionadas & Resultados & Triangulación con la hermenéutica del turismo \\
\hline $\begin{array}{l}\text { Género-Importancia de } \\
\text { proyección de la imagen }\end{array}$ & $\begin{array}{l}\text { Tanto los individuos de } \\
\text { género masculino como } \\
\text { femenino concuerdan en } \\
\text { que la imagen turística es } \\
\text { de alta importancia previo } \\
\text { escoger un destino. }\end{array}$ & $\begin{array}{l}\text { En este resultado se evidencia, así como lo afirma } \\
\text { Boyer en su teoría lúdico o motivacional, el turista va a } \\
\text { proyectar en su mente lo que este aspira vivir y } \\
\text { experimentar, es decir, que previo a realizar una visita, } \\
\text { el viajero establecerá en su imaginación una perspectiva } \\
\text { anhelada. } \\
\text { De igual forma Lynch, en su teoría hace alusión a la } \\
\text { imagen urbana que comprende varios elementos que } \\
\text { caracterizan de forma inigualable un lugar con carácter } \\
\text { estructurado. }\end{array}$ \\
\hline $\begin{array}{l}\text { Género-Importancia de } \\
\text { conocimiento previo del } \\
\text { destino }\end{array}$ & $\begin{array}{l}\text { Tanto los individuos de } \\
\text { género masculino y } \\
\text { femenino consideran que } \\
\text { es altamente importante } \\
\text { tener información y } \\
\text { conocimientos previo del } \\
\text { destino que se va a visitar }\end{array}$ & $\begin{array}{l}\text { Sustentando este resultado en base al modelo } \\
\text { establecido por Krippendorf, sobre la existencia de la } \\
\text { Sociedad Industrial, se hace alusión a las expectativas } \\
\text { que los turistas desarrollan en su imaginación previo a } \\
\text { realizar una investigación del destino, obteniendo } \\
\text { información acerca del mismo, por lo cual con } \\
\text { información previa surge una expectativa que lo motiva } \\
\text { a viajar. }\end{array}$ \\
\hline $\begin{array}{l}\text { Edad-Elementos para la } \\
\text { decisión del viaje }\end{array}$ & $\begin{array}{l}\text { Tanto menores de } 18 \text { años } \\
\text { como mayores de } 50 \text { años, } \\
\text { deciden visitar un destino } \\
\text { por los atractivos turísticos } \\
\text { principalmente. }\end{array}$ & $\begin{array}{l}\text { En base al Sistema Turístico de Cuervo, este es un } \\
\text { conjunto que se conforma por subconjuntos, mismos } \\
\text { que son la movilización, hospedaje, servicios de } \\
\text { intermediación, prestadores de servicios turísticos, } \\
\text { restauración, etc. mismos que son parte de los servicios } \\
\text { turísticos y son determinantes para elegir un destino. De } \\
\text { igual forma, Boullon expone que un espacio turístico } \\
\text { debe presentar atractivos turísticos, mismos que } \\
\text { componen la planta turística y son elementos decisivos } \\
\text { para elegir un destino a visitar. }\end{array}$ \\
\hline
\end{tabular}


Tabla 3

Análisis de Resultados (continuación)

\begin{tabular}{|c|c|c|}
\hline Variables correlacionadas & Resultados & Triangulación con la hermenéutica del turismo \\
\hline $\begin{array}{l}\text { Nivel } \\
\text { Destinos } \\
\text { visitados }\end{array}$ & $\begin{array}{l}\text { Las personas con ingresos } \\
\text { económicos entre salario } \\
\text { mínimo a } 800 \$ \text { han } \\
\text { realizado viajes a EE. UU., } \\
\text { Colombia y México. }\end{array}$ & $\begin{array}{l}\text { Como lo expone Urry, en su teoría de la Mirada } \\
\text { Turística, se considera al turismo como un fenómeno } \\
\text { moderno, que incita a realizar viajes enfocado en } \\
\text { diversas motivaciones y que el turista necesita al estar } \\
\text { en una sociedad con cambios progresivos, además de } \\
\text { que realizar un viaje aporta conocimientos } \\
\text { permitiéndole ser parte de un grupo social o } \\
\text { posicionándolo en tal. En este sentido el resultado se } \\
\text { complementa con el Sistema Turístico de Molina, en el } \\
\text { que varios subsistemas conforman un sistema, dentro } \\
\text { de esto comprende la estructura económica de una } \\
\text { organización que retribuye monetariamente al sector } \\
\text { público o privado. }\end{array}$ \\
\hline Nivel Educativo- Asesoría & $\begin{array}{l}\text { Sin importar la instrucción } \\
\text { educativa, las personas se } \\
\text { asesoran con } \\
\text { amigos/familiares, } \\
\text { internet, y escasamente en } \\
\text { agencias de viajes. }\end{array}$ & $\begin{array}{l}\text { En este resultado se puede evidenciar que no existe una } \\
\text { utilización del sistema turístico de Cuervo, puesto que } \\
\text { entre la oferta Cuervo considera a las Agencias de } \\
\text { viajes, y en este resultado se ve que este elemento de } \\
\text { servicios de intermediación esta entre los últimos para } \\
\text { solicitar una asesoría previo a un viaje. }\end{array}$ \\
\hline $\begin{array}{l}\text { Nivel } \\
\text { Beneficios }\end{array}$ & $\begin{array}{l}\text { Todas las personas sin } \\
\text { distinción de instrucción } \\
\text { educativa consideran que } \\
\text { el beneficio de viajar es } \\
\text { emocional. }\end{array}$ & $\begin{array}{l}\text { Contemplando el criterio de Iso Ahola, en el modelo de } \\
\text { la psicología social para el turismo, existe una } \\
\text { motivación y beneficio en cada viaje por lo que tanto } \\
\text { las razones como sus beneficios están relacionados } \\
\text { íntimamente que establecen el comportamiento del } \\
\text { turista. }\end{array}$ \\
\hline $\begin{array}{l}\text { Estado civil- Elección } \\
\text { lugar nacional }\end{array}$ & $\begin{array}{lr}\text { Todos los } & \text { grupos } \\
\text { pertenecientes a } & \text { estado } \\
\text { civil, tienen como } & \text { opción } \\
\text { principal } & \text { visitar } \\
\text { Galápagos. } & \end{array}$ & $\begin{array}{l}\text { Como expone Gunn, en el Modelo de atracción } \\
\text { turística, estos se consideran como la parte esencial de } \\
\text { la actividad turística que se complementa con los } \\
\text { servicios turísticos complementarios. De igual forma } \\
\text { Crompton, con su Modelo de Elección de Destinos, } \\
\text { estipula que el turista, ya tiene pensado un destino el } \\
\text { cual es considerado como potencial, puesto que este ya } \\
\text { tiene un conocimiento previo sobre el lugar. Siempre el } \\
\text { turista tiene una selección de destinos que puede ser } \\
\text { elegidos, sin embargo, solo uno llega a ser elegido, los } \\
\text { otros pueden ser considerados, y hay otros que son } \\
\text { descartados desde el inicio. }\end{array}$ \\
\hline
\end{tabular}

Fuente: Ortiz (2021)

\section{Conclusiones}

- La investigación permite establecer que el imaginario del turista, si tiene relación con la oferta de los servicios turísticos, y la elección de un destino se ve reflejada principalmente por los atractivos turísticos que existen en el destino turístico, y en menor escala influye la infraestructura hotelera, de restauración, transporte, servicios de mediación e incluso la calidad del servicio. 
- En el imaginario del turista, la proyección de la imagen general de un destino, así como en los aspectos políticos, culturales, sociales, ambientales, culturales y de seguridad es realmente importante, por lo que dichos ámbitos son de mayor influencia para la elección de visita a un destino turístico previo a obtener información acerca del mismo.

- Los destinos turísticos se posicionan en el imaginario del turista como los que pueden ser considerados potenciales y aquellos que se descartan, para llegar a una decisión final de elección de destinos, influyen las motivaciones que este tenga, mismas que pueden ser personales, donde no existe una influencia del entorno y se busca generar un conocimiento a través de la experiencia; las motivaciones familiares que se centran en fortalecer lazos familiares y las motivaciones sociales, donde un entorno influye en el comportamiento y decisión del individuo.

- Las agencias de viajes turísticas ofertan y comercializan principalmente en el contexto internacional a destinos como Estados Unidos, México y Europa (España y Turquía), mientras que en el contexto nacional el destino más comercializado y posicionado en la memoria colectiva de Ambato, son las Islas Galápagos y la región Amazónica, en segunda instancia.

\section{Referencia Bibliográfica}

Antonietti, B. (2017). Servicios Turísticos I. Argentina: UTN. <http://utntyh.com/wpcontent/uploads/2017/09/La-informaci\%C3\%B3n-Tur\%C3\%ADstica.pdf>

Araujo, G. \& Sevilla, M. (2017). Los viajeros y sus motivaciones. Estudios y Perspectivas en Turismo, pp.62-85. <https://www.redalyc.org/pdf/1807/180749182004.pdf>

Camara, C. \& Morcate, F. (2015). Metodología para la identificación, clasificación y evaluación de los recursos territoriales turísticos del centro de ciudad de Fort-deFrance. Arquitectura

$$
y
$$

Urbanismo, 35(1),

48-67. http://scielo.sld.cu/scielo.php?script=sci_arttext\&pid=S1815$58982014000100005 \& \operatorname{lng}=$ es\&tlng=es.

Carvajal, G. \& Lemoine, F. (2018). Análisis de los atractivos y recursos turísticos del cantón San Vicente. El periplo sustentable, (34), 164-184 http://www.scielo.org.mx/scielo.php?script=sci_arttext\&pid=S187090362018000100164\&lng=es\&tlng=es.

Casanova, Ferro, G. (2016). Derecho y turismo. Fundación Proturismo. https://elibro.net/es/lc/uta/titulos/78930 
Castellucci, D. (2016). Sistemas de calidad en turismo. Argentina, pp.15-29. <http://nulan.mdp.edu.ar/1330/1/castellucci_di.pdf>

Crompton, J. (1992). Attitude determinants in tourism destination choice. Annals of Tourism Research, pp. 17, 432-448.

Decasper, S. \& Servalli, N. (2016). Imaginarios turísticos: Argentina para el turista brasileño. Turismo $\quad y \quad$ Sociedad, $\quad$ XVIII, pp. $\quad 43-60$. DOI: http://dx.doi.org/10.18601/01207555.n18.03

Echeverría, B. (2019). Definición de la cultura. FCE - Fondo de Cultura Económica. https://elibro.net/es/lc/uta/titulos/123965

Garcia, A. (2021). Clasificación de los recursos turísticos. Igeograf.unam.mx. <http://www.igeograf.unam.mx/Geodig/antologia/index.html/pdf/2_garcia.pdf>

González, P. (2016). Producto Turístico. $\quad$ Escolme.edu.co. $<$ https://www.escolme.edu.co/almacenamiento/oei/tecnicos/guianza/contenido_u 4.pdf>

Goycoolea, R. (2016). Imaginarios turísticos y configuración.Serbal.pntic.mec.es. <http://serbal.pntic.mec.es/AParteRei/roberto44.pdf>

Magadán, Díaz, M. (2016). Estructura, economía y política turística. Septem Ediciones. https:/elibro.net/es/lc/uta/titulos/42020

Mantecón, A. \& Álvarez-Sousa, A. (2019). Sociología del turismo. CIS - Centro de Investigaciones Sociológicas. https://elibro.net/es/lc/uta/titulos/124015

Millet, O. (2016). La imagen de un destino turístico como herramienta de marketing. <https://dialnet.unirioja.es/descarga/libro/482050.pdf>.

Ministerio de Turismo [MINTUR]. (2017). Manual para la realización del inventario de atractivos. 2nd ed. Quito. <https://servicios.turismo.gob.ec/descargas/InventarioAtractivosTuristicos/Parte 1_GuiaMetodologicaInventarioGeneracionEspacioTuristico2017_2daEd.pdf>

Ministerio de Turismo [MINTUR]. (2018a). Manual de Atractivos Turísticos. $<$ https://servicios.turismo.gob.ec/descargas/InventarioAtractivosTuristicos/manualatractivos-turisticos.pdf $>$

Ministerio de Turismo [MINTUR]. (2021). Reglamento de Alojamiento Turístico. Siete.turismo.gob.ec.

<https://siete.turismo.gob.ec/reglamento/reglamento\%20de\%20alojamiento\%20t uristico.pdf 
Ministerio de Turismo [MINTUR]. (2018b). Desarrollo de Destinos y Servicios Turísticos. <https://www.turismo.gob.ec/wp-content/uploads/2020/02/Anexo-0.13-11-19_proy_destinos_servicios.pdf>

Navarro, D. (2015). Recursos y atractivos turísticos: conceptualización, clasificación y valoración. Cuadernos de Turismo, pp.335-357. <https://www.redalyc.org/pdf/398/39838701014.pdf>

Ortiz, Martínez, J. (2021). E imaginario del turista y la oferta turística del cantón Ambato. (Tesis de pregrado). Ambato: Universidad Técnica de Ambato.

Pons, R. (2017). La imagen del destino y el comportamiento de compra del turista. Teoría y Praxis, (3), pp.89-102. <https://www.redalyc.org/pdf/4561/456145111008.pdf>

Ricaurte, C. (2019). Manual de diagnóstico turístico local. Mastor.cl. $<$ http://mastor.cl/blog/wp-content/uploads/2018/07/Ricaurte.-Manualdiagnostico-turistico-local.-Guia-planificadores.-2000.-50-pgs.pdf >

Sancho, A. (1994). Introducción al Turismo. Utntyh.com. <http://www.utntyh.com/wpcontent/uploads/2011/09/introduccion-al-turismo-omt.pdf>

Valdez, R. (2002). Elección de destinos Turísticos: influencia del grado de implicación y conocimientos previos de turistas. Revista Turismo em Análise, 13(2), p.17.

Zamudio, L. (2019). Los imaginarios en la percepción de los lugares turísticos. 2(1), pp.114-137. <https://dialnet.unirioja.es/descarga/articulo/4781288.pdf>.

\section{LCiencia}


El artículo que se publica es de exclusiva responsabilidad de los autores y no necesariamente reflejan el pensamiento de la Revista Conciencia Digital.

\section{Ciencia}

El artículo queda en propiedad de la revista y, por tanto, su publicación parcial y/o total en otro medio tiene que ser autorizado por el director de la Revista Conciencia Digital.
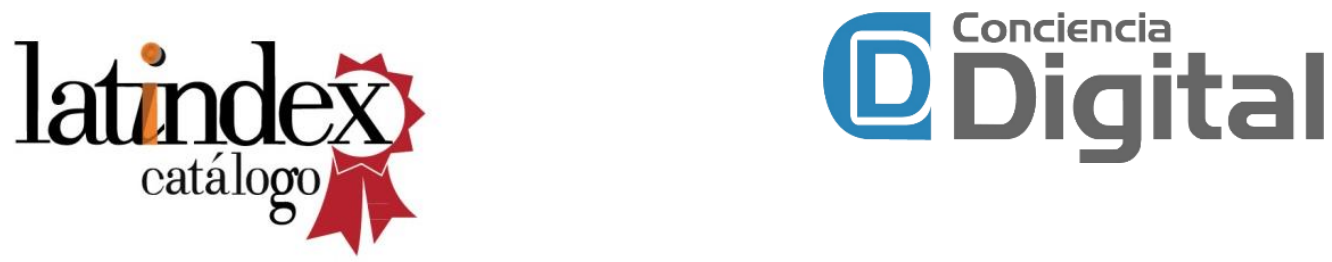

Indexaciones

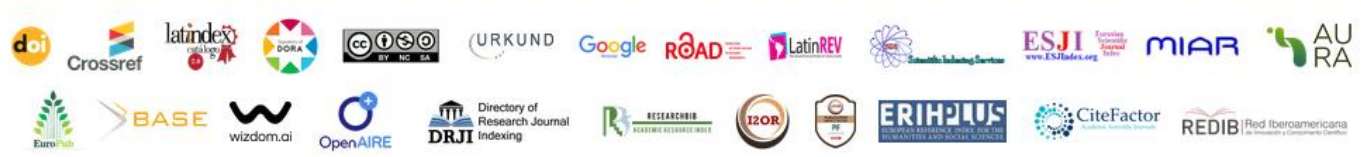

